\title{
Glycaemic Status On Admission In Patients With Acute Coronary Syndrome
}

MGCP Marasinghe*, J Indrakumar*

*Faculty of Medical Sciences, University of Sri Jayewardenepura

\begin{abstract}
Introduction: In patients with acute coronary syndrome (ACS), hyperglycemia is a predictor of immediate and long-term cardiovascular mortality. Abnormal glucose regulation is present in the majority of these patients and is unrecognized in up to half of the cases. The objective of this study was to assess the glycaemic status of patients on admission with ACS.

Methodology: Patients presenting with chest pain and falling into one of the acute coronary syndromes (STEMI, NSTEMI, and UA) were allocated in to two groups based on past history of Diabetes. Diagnosed Diabetic patients who were not on treatment were excluded from the study. Admission RBS and next day FBS were recorded in all patients.

Results: 102 patients were enrolled for the study. Mean admission random blood sugar(RBS) and fasting blood sugar(FBS) of diabetic patients who were on treatment were significantly higher $(308,203 \mathrm{mg} / \mathrm{dl})$ than that of patients without a past history of Diabetes $(135,111$ $\mathrm{mg} / \mathrm{dl}) \mathrm{P}<0.001$. Out of the patients with diabetes, $88 \%$ had a RBS more than $140 \mathrm{mg} / \mathrm{dl}$ and $59 \%$ had more than $200 \mathrm{mg} / \mathrm{dl}$ on admission. Patients without past history of Diabetes, these values were $32 \%$ and $5 \%$ respectively. $45 \%$ of patients without past history of Diabetes had impaired FBS values $(100-126 \mathrm{mg} / \mathrm{dl})$ and $17 \%$ had a FBS value more than $126 \mathrm{mg} / \mathrm{dl}$. The blood glucose values (RBS and FBS) of each of the three types of ACSs (STEMI, NSTEMI, UA) did not show a significant difference among them.

Conclusions: Hyperglycaemia is a major problem in our patients with and without a past history of diabetes when they present with ACS. Therefore prompt attention is necessary on blood glucose control in all patients, irrespective of the past status of diabetes. It is important to follow up the patients with abnormal blood glucose values and without a past history of diabetes, to detect the development of Diabetes.
\end{abstract}

\section{Introduction}

In patients with acute coronary syndrome (ACS) ${ }^{1}$, hyperglycemia has been shown to be a predictor of immediate and long-term cardiovascular mortality ${ }^{2}$. Abnormal glucose regulation is present in the majority of ACS patients and is unrecognized in up to half of the cases ${ }^{3}$. Recent studies have addressed the impact of abnormal glucose metabolism in the acute phase of patients ACS and without diabetes ${ }^{4}$. The entity of impaired fasting glucose (IFG) is not only an independent factor of cardiovascular mortality, it has also been associated with a doubling of the risk of in-hospital mortality in ACS 5, 6. It has also been found that stress hyperglycaemia due to myocardial infarction is associated with an increased risk of in-hospital mortality in patients with and without diabetes ${ }^{7}$. Recent trials have shown that in patients with ACS, the combination of fasting blood sugar (FBS) more than $110 \mathrm{mg} / \mathrm{dl}$ and an admission random blood sugar (RBS) of more than $140 \mathrm{mg} / \mathrm{dl}$ identifies patients who are prone to developing Diabetes later 8,9 .

There is no published data in Sri Lanka regarding hyperglycaemia in patients presenting with ACS. There seams to be rise in prevalence of diabetes in Sri Lanka and this may have a significant impact on the prognosis of patients with ACS. The main objective of this study was to assess the glycaemic status of the patients with diabetes and patients without a past history of diabetes, on admission with ACS.

Correspondence: J. Indrakumar, Faculty of Medical Sciences, University of Sri Jayawardanepura, Sri Lanka. Email:sathrika@sltnet.lk 


\section{Methods}

During the period of 6 months (from 01.08.2008 to 01.02.2009), 102 consecutive patients with ACS, admitted to the University Medical Unit of the Colombo South Teaching Hospital were enrolled to the study. The patients were categorized in to two groups. One group consisted of patients with a past history of diabetes and who were on regular treatment. The second group was patients without a history of diabetes. Patients with diabetes and not on regular diabetic treatment were excluded from the study. Patients with ACS consisted of three groups, namely ST elevated myocardial infarction (ECG showing ST segment elevation with positive troponin test), non-ST elevated myocardial infarction (ST depression / $\mathrm{T}$ inversion with positive troponin test) and unstable angina (ST depression / $\mathrm{T}$ inversion with negative troponin test). Ethical Clarence was obtained from the ethical review committee of the Colombo South Teaching Hospital. Informed consent was taken from all the subjects who were enrolled.

An interviewer administered questionnaire was filled by a trained doctor. Patient's age, sex, details of the presenting complaints, past history of diabetes, drugs for diabetes were obtained. An ECG and a troponin test were done in all patients. Random blood glucose test was done within one hour of admission. Next day fasting blood glucose test was done in all patients. Data analysis was done with the help of SPSS 13.0 for windows statistical analysis package.

\section{Results}

Characteristics of the patients are shown in the Table 1.The mean RBS values of the patients with and without a past history of diabetes were $308 \mathrm{mg} / \mathrm{dl}$ and $135 \mathrm{mg} / \mathrm{dl}$ respectively $(\mathrm{P}<0.001)$. The mean FBS of known patients with and without a past history of diabetes were $203 \mathrm{mg} / \mathrm{dl}$ and 111 $\mathrm{mg} /$ dl respectively $(\mathrm{P}<0.001)$.

Eighty eight percent of the patients with diabetes had admission RBS more than $140 \mathrm{mg} / \mathrm{dl}$ and 59\% had more than 200 $\mathrm{mg} / \mathrm{dl}$. Of the patients without a past history of diabetes, $32 \%$ had admission RBS value more than $140 \mathrm{mg} / \mathrm{dl}$ and 5.7\% had an admission RBS value more than $200 \mathrm{mg} / \mathrm{dl}$.

Table 1. Patient characteristics.

\begin{tabular}{|ll|}
\hline $\begin{array}{l}\text { Number of Patients } \\
\text { Age }\end{array}$ & Sample details \\
Sex & $20-80 y r s$ (mean 61) \\
$\quad$ Male patients & 52 \\
$\quad$ Female patients & 50 \\
Type of ACS & \\
$\quad$ STEMI & $35(34.3 \%)$ \\
$\quad$ NSTEMI & $32(31.4 \%)$ \\
UA & $35(34.3 \%)$ \\
$\begin{array}{l}\text { Past history of } \\
\text { diabetes mellitus }\end{array}$ & \\
$\quad$ Yes & \\
No & $49(48 \%)$ \\
\hline
\end{tabular}

It was found that the $17 \%$ of patients without a past history of diabetes had a FBS value above $126 \mathrm{mg} / \mathrm{dl}$ and $26 \%$ in the range of $100-126 \mathrm{mg} / \mathrm{dl}$.

The mean admission RBS values of STEMI, NSTEMI and UA were $188 \mathrm{mg} / \mathrm{dl}$, $233 \mathrm{mg} / \mathrm{dl}, 169 \mathrm{mg} / \mathrm{dl}$ respectively $(\mathrm{P}=$ 0.12 ). The mean FBS values of STEMI, NSTEMI and UA were $146 \mathrm{mg} / \mathrm{dl}, 189 \mathrm{mg} / \mathrm{dl}$, $139 \mathrm{mg} / \mathrm{dl}$ respectively $(\mathrm{P}=0.07)$. The results are summarized in Table 2 .

\section{Discussion}

Diabetes mellitus is an established risk factor of poor prognosis of ACS and good glycemic control is valuable for a better outcome ${ }^{10}$. Admission blood glucose measurement allows planning therapeutic decisions at the acute phase. Stress hyperglycemia could also be a contributory factor in the causation of hyperglycaemia.

In this study, we found that the glycaemic control of known diabetic patients on treatment was unsatisfactory. This could partly be due to the result of acute stress (stress hyperglycaemia) in those with proper diabetic control before the admission. The presence of hyperglycaemia in patients without a past diagnosis of diabetes was an interesting finding. Whether these patients had a significant stress hypeglycaemia or whether they were mainly undiagnosed patients with diabetes is debatable. Follow up studies and assessment of $\mathrm{HbA1c}$ levels of this 
Table 2. Blood glucose values in the patients studied

\begin{tabular}{|c|c|c|c|}
\hline & $\begin{array}{l}\text { Patients with a past } \\
\text { history of diabetes }\end{array}$ & $\begin{array}{l}\text { Patients without a } \\
\text { past history of } \\
\text { diabetes }\end{array}$ & $\begin{array}{l}\text { Significance } \\
\text { (P value) }\end{array}$ \\
\hline $\begin{array}{l}\text { Mean RBS (SD) mg/dl } \\
\text { Mean FBS (SD) mg/dl }\end{array}$ & $\begin{array}{l}308(167) \\
203(87)\end{array}$ & $\begin{array}{l}135(36) \\
111(18)\end{array}$ & $\begin{array}{l}<0.001 \\
<0.001\end{array}$ \\
\hline $\begin{array}{l}\text { RBS }(\mathrm{mg} / \mathrm{dl}) \\
<110 \\
110-140 \\
141-200 \\
>200\end{array}$ & $\begin{array}{l}02(4.1 \%) \\
04(8.2 \%) \\
14(28.6 \%) \\
29(59.2 \%)\end{array}$ & $\begin{array}{l}11(20.7 \%) \\
25(47.1 \%) \\
14(26.4 \%) \\
03(5.7 \%)\end{array}$ & \\
\hline $\begin{array}{l}\text { FBS (mg/dl) } \\
<100 \\
100-110 \\
111-126 \\
>126\end{array}$ & $\begin{array}{l}03(6.1 \%) \\
05(10.2 \%) \\
06(12.2 \%) \\
35(71.4 \%)\end{array}$ & $\begin{array}{l}20(37.7 \%) \\
10(18.9 \%) \\
14(26.4 \%) \\
09(17.0 \%)\end{array}$ & \\
\hline
\end{tabular}

population will help to resolve this question.

High prevalence of impaired fasting glucose tolerance in patients with ACS indicates that this is an important event to screen all with a FBS test. Treating them early (at least life style modification) will improve the long term mortality and morbidity and may prevent progression to diabetes ${ }^{11}, 12$. The observation that the sub types of ACS (STEMI, NSTEMI, UA) did not show a significant difference in the blood glucose values suggest that the degree of myocardial necrosis do not directly

\section{References}

1. Russell V. Luepker, Fred S. Apple, Robert H Christension, Richard S. Crow, Stephen P. Fortmann, David Goff, et al. Case Definitions for Acute Coronary Heart Disease in Epidemiology and Clinical Research Studies. A Statement From the AHA Council on Epidemiology and Prevention. Circulation 2003; 108: 2543-2549

2. Malmberg K, Rydén L. Myocardial infarction in patients with diabetes mellitus. Eur Heart J 1988; 9:259-264

3. Coutinho M, Gerstein HC, Wang Y, Yusuf S. The relationship between glucose and incident cardiovascular events: a metaregression analysis of published data from 20 studies of 95,783 correlate with the raised blood glucose levels.

This study illustrates that hyperglycaemia is a major problem in ACS patients, with and without a past history of diabetes, particularly so in those already known to have diabetes. Therefore, prompt attention is necessary to control blood glucose in all these patients, irrespective of the past status of diabetes. It is important to follow up the patients with abnormal blood glucose values and without a past history of diabetes, to detect the development of Diabetes.

individuals followed for 12.4 years. Diabetes Care 1999;22:233-240

4. Deedwania P, Kosiborod M, Barrett E, Ceriello A, Isley W, Mazzone T, Raskin P. Hyperglycemia and acute coronary syndrome: a scientific statement from the American Heart Association Diabetes Committee of the Council on Nutrition, Physical Activity, and Metabolism. Anesthesiology2008; 109(1):14-24.

5. Chih S, McQuillan BM, Kaye J, Beilby JP, Hung J. Abnormal glucose regulation in an Australian acute coronary syndrome population: a prospective study. Diabetes Res Clin Pract 2008; 81(3):303-9. Epub 2008 Jun 20.

6. Rioufol G, Zeller M, Oudot A, L'Huillier I, Buffet $\mathrm{P}$, Beer JC, et al. Predictive value 
of glycemia in acute coronary syndromes. Arch Mal Coeur Vaiss. 2004 Dec; 97 Spec No 3:47-50.

7. Capes SE, Hunt D, Malmberg K, Gerstein HC. Stress hyperglycaemia and increased risk of death after myocardial infarction in patients with and without diabetes: a systematic overview.Lancet 2000; 355(9206):7738.

8. Hadjadj S, Coisne D, Mauco G, Ragot S, Duengler F, Sosner P, et al. Prognostic value of admission plasma glucose and $\mathrm{HbA}$ in acute myocardial infarction. Diabet Med 2004; 21(4):305-10.

9. Okosieme OE, Peter R, Usman $\mathrm{M}$, Bolusani H, Suruliram P, George L,Evans LM. Can admission and fasting glucose reliably identify undiagnosed diabetes in patients with acute coronary syndrome? Diabetes Care 2008;31(10):1955-9.
10. Malmberg, K, Norhammar, A, Wedel, H, Ryden L. Glycometabolic state at admission: Important risk markers of mortality in conventionally treated patients with diabetes mellitus and acute myocardial infarction. Long-term results from the Diabetes and InsulinGlucose Infusion in Acute Myocardial Infarction (DIGAMI) study. Circulation 1999; 99:2626-2632

11. Diabetes Prevention Program Research Group. Reduction in the incidence of type 2 diabetes with lifestyle intervention or metformin. $\mathrm{N}$ Engl J Med 2002; 346:393-403.

12. Tuomilehto J et al, Prevention of type 2 diabetes mellitus by changes in lifestyle among subjects with impaired glucose tolerance. N Engl J Med 2001; 344: 1343-1350. 